Marine Biotechnology

October 2009, Volume 11, Number 5

http://dx.doi.org/10.1007/s10126-008-9173-y

(c) 2009 Springer. Part of Springer Science+Business

Media
Archimer, archive institutionnelle de l'Ifremer http://www.ifremer.fr/docelec/

The original publication is available at http://www.springerlink.com

\title{
Combining Two-Stage Testing and Interval Mapping Strategies to Detect QTL for Resistance to Bonamiosis in the European Flat Oyster Ostrea edulis
}

\author{
D. Lallias ${ }^{1,2,{ }^{*}}$, L. Gomez-Raya ${ }^{3}$, C. S. Haley ${ }^{4,5}$, I. Arzul $^{1}$, S. Heurtebise ${ }^{1}$, A. R. Beaumont ${ }^{2}$, P. Boudry ${ }^{6}$ \\ and $S$. Lapègue ${ }^{1}$
}

${ }^{1}$ Laboratoire Génétique et Pathologie, Ifremer, Ronce-les-bains, 17390 La Tremblade, France

${ }^{2}$ School of Ocean Sciences, College of Natural Sciences, Bangor University, Askew Street, Menai Bridge, Anglesey, LL59 5AB, UK

${ }^{3}$ Department of Animal Biotechnology, University of Nevada, Reno, NV 89557, USA

${ }^{4}$ Roslin Institute and Royal (Dick) School of Veterinary Studies, University of Edinburgh, Roslin BioCentre, Midlothian, EH25 9PS, UK

${ }^{5}$ MRC Human Genetics Unit, Western General Hospital, Edinburgh, EH4 2XU, UK

${ }^{6}$ UMR M100 Physiologie et Ecophysiologie des Mollusques Marins, Ifremer, Plouzané, France

*: Corresponding author : D. Lallias, email address : d.lallias@bangor.ac.uk

\begin{abstract}
:
We have identified quantitative trait loci (QTL) in the flat oyster (Ostrea edulis) for resistance to Bonamia ostreae, a parasite responsible for the dramatic reduction in the aquaculture of this species. An $F_{2}$ family from a cross between a wild oyster and an individual from a family selected for resistance to bonamiosis was cultured with wild oysters injected with the parasite, leading to $20 \%$ cumulative mortality. Selective genotyping of 92 out of a total of $550 \mathrm{~F}_{2}$ progeny (i.e., 46 heavily infected oysters that died and 46 parasite-free oysters that survived) was performed using 20 microsatellites and 34 amplification fragment length polymorphism primer pairs. Both a two-stage testing strategy and QTL interval mapping methods were used. The two-stage detection strategy had a high power with a low rate of false positives and identified nine and six probable markers linked to genes of resistance and susceptibility, respectively. Parent-specific genetic linkage maps were built for the family, spanning ten linkage groups $(n=10)$ with an observed genome coverage of $69-84 \%$. Three QTL were identified by interval mapping in the first parental map and two in the second. Good concordance was observed between the results obtained after the two-stage testing strategy and QTL mapping.
\end{abstract}

Keywords: Ostrea edulis - Disease resistance - QTL mapping - Survival analysis - Statistical power 


\section{Introduction}

Genetic and genomic tools, such as QTLs and candidate genes, increasingly contribute to improve the efficiency of selective breeding programs in aquaculture species (Liu and Cordes 2004). In cultured bivalves, genetic maps have been established for the Pacific oyster Crassostrea gigas (Hubert and Hedgecock 2004; Li and Guo 2004), the Zhikong scallop Chlamys farreri (eg Li et al. 2005), the blue mussel Mytilus edulis (Lallias et al. 2007a) and the European flat oyster Ostrea edulis (Lallias et al. 2007b). However, the mapping of quantitative trait loci (QTL) onto those genetic maps has rarely been achieved in bivalves (eg in C. virginica, Yu and Guo 2006).

The flat oyster Ostrea edulis is a species endemic to European coasts, both Atlantic and Mediterranean. It has been introduced into USA, Canada and Japan (Ruesink et al. 2005) but most of its production is located in Europe. Its worldwide aquaculture production decreased from around 30,000 tons in the 1960's to 6,000 tons today mainly due to two parasitic diseases, marteiliosis and bonamiosis. Bonamiosis is an intrahaemocytic parasitosis due to the protist Bonamia ostreae of the phylum Cercozoa (Cavalier-Smith and Chao 2003). In Europe, it was first observed in Brittany (France) and was then reported in other European countries.

Since 1985, Ifremer (Institut français de recherche pour l'exploitation de la mer) has been undertaking a selective breeding program for resistance to bonamiosis (NaciriGraven et al. 1998). Similarly, selective breeding was also initiated in Ireland (Culloty et al. 2004). The families selected in France showed enhanced survival and a lower prevalence of the parasite compared with control oysters in Bonamia-contaminated areas; the relative performances of the selected, back-crossed and control families suggested an additive genetic component for the trait (Bédier et al. 2001). However, the heritability of this trait remains to be estimated because of the technical difficulties of required experiments. In this context, the identification of QTL of resistance/susceptibility to bonamiosis would contribute to a better understanding of the genetic basis of this trait and enable an estimation of the potential of marker-assisted selection (MAS). MAS would be a valuable tool to accelerate the selective breeding process by increasing the trait response between two generations of selection.

The primary aim of our study was to identify QTL for resistance or susceptibility to bonamiosis in $O$. edulis. This relied on a 6-month trial challenge experiment in which wild oysters (injected with high concentrations of purified $B$. ostreae) were cultured with the tested oysters ( $F_{2}$ segregating family) in order to transmit bonamiosis from the wild oysters to the tested oysters. Two extreme phenotypic classes were scored at microsatellite and AFLP markers: heavily infected oysters that died during the challenge experiment (susceptible to the disease) and oysters that survived and in which no parasite could be detected (non-susceptible to the disease).

A two-stage testing strategy was firstly performed (Moen et al. 2004). It is based on a Transmission Disequilibrium Test (TDT) on animals susceptible to the disease followed by a survival analysis test using all animals (susceptible and non-susceptible). This method can reduce the rate of false positives (detection of a QTL when there is none) whilst reducing the genotyping effort by genotyping only the susceptible ones. However, Moen et al. (2004) did not explore the impact of their two-stage testing strategy on statistical power of detecting a QTL. Moreover, in most settings, multiple loci are mapped and it is of interest to know the power for detection of multiple susceptibility loci, as well as the rate of false positives when carrying out multiple testing. Therefore, power and rate of false positives were computed for two-stage selection strategies in multi testing schemes aimed at mapping multiple susceptibility genes. 
Finally, a regression interval mapping analysis (Haley and Knott 1992) was performed for identifying and mapping QTL of resistance or susceptibility to the disease. Both analyses (two-stage testing strategy and regression interval mapping), aim to link genotypes (different alleles of molecular markers) to phenotypes (rapidity of death, level of infection to the parasite). Results obtained with those two approaches were compared and the value of each discussed in the context of QTL mapping for disease resistance in aquaculture species.

\section{Materials and methods}

Segregating family

The family used in this study was initiated in 2004 by crossing a wild-type oyster (W31) and an oyster (98AC703-29) from one of the selected families that were produced by Ifremer during the selective breeding program to bonamiosis. Two full-sibs from this $F_{1}$ family were then crossed to make the F2 segregating family (OE.F2.05.04). This family was chosen, among several similar families, based on DNA polymorphism of microsatellite markers for the grand-parents and $F_{1}$ parents (410_7 and 410_8), and after parentage checking. Female flat oysters are brooding their larvae into the mantle cavity. Therefore controlled crosses can only be performed by putting two oysters in a tank, and collecting the larvae on a sieve. Therefore the female and male parents were not identified.

\section{Bonamia ostreae challenge experiment}

The experimental design consisted of 5 raceways each containing 110 oysters (8 monthold at the beginning of the experiment) from the segregating family and 44 wild oysters. A cohabitation experiment was chosen because it mimics the mode of the disease transmission in nature (Lallias et al. 2008). The 6-month cohabitation experiment was started in mid-January 2006 by injecting $1 \times 10^{6}$ cells of purified parasites into the heart cavity of the wild oysters (from Quiberon bay, Brittany, France). Mortality was checked daily and total shell length (from hinge to outer shell edge) of each dead oyster was measured. Heart smears were performed on the dead oysters and the level of parasitic infection was characterized: no infection $\left(\mathrm{BO}^{-}\right)$, low infections $\left(\mathrm{BO}^{+}\right)$, moderate infections $\left(\mathrm{BO}^{++}\right)$or heavy infections $\left(\mathrm{BO}^{+++}\right)$. The challenge experiment was terminated in August 2006 when heart smears were carried out on all of the surviving oysters from the segregating family. Full details of the cohabitation challenge experiment are detailed in Lallias et al. (2008).

In addition to assessing parasitic infection levels by heart smear, PCR tests were carried out on a random subset of oysters by using the primer pairs BO/BOAS (Cochennec et al. 2000) that amplify a portion of the 18S rDNA of the parasite. Agarose gel (2\%) electrophoresis was performed on PCR products alongside to a 100-bp molecular weight standard. Samples containing $B$. ostreae exhibited a 300-bp band.

\section{Genotyping}

Samples from the mapping family consisted of the 2 grand-parents (98AC703-29 and W31), the $2 F_{1}$ parents (410_7 and 410_8) together with $46 F_{2}$ progeny that died highly infected with the parasite (heart smear $\mathrm{BO}^{+++}, \mathrm{PCR}$ positive) and $46 \mathrm{~F}_{2}$ progeny that survived (heart smear B0-, PCR negative). 
DNA was extracted from gill tissue using a standard chloroform extraction (Sambrook et al. 1989) followed by purification with the Wizard ${ }^{\circledR}$ DNA Clean-Up System (Promega). Quality and concentration of DNA was assessed using a spectrophotometer and by running a small sample on a $2 \%$ agarose gel.

Twenty microsatellite markers selected from those developed by Naciri et al. (1995), Morgan et al. (2000), Morgan and Rogers (2001), Sobolewska et al. (2001) and Launey et al. (2002) were amplified by polymerase chain reaction (PCR) according to the authors' protocols.

AFLP analysis was performed by using a modified version of Vos et al. (1995), in which digestion and ligation were achieved in the same mix being incubated for 16 hours at $16^{\circ} \mathrm{C}$. Thirty four AFLP primer pairs were genotyped in the mapping family. Electrophoresis and data collection were carried out on an ABI 3100-Avant (Applied Biosystems). Electrophoresis parameters were set at injection for $15 \mathrm{~s}$ at $15 \mathrm{kv}$, running for $25 \mathrm{~min}$ at $15 \mathrm{kv}$ and $60^{\circ} \mathrm{C}$, with POP4 polymer. Data were analysed with GeneMapper ${ }^{\circledR}$ software version 3.7 and individuals were scored for the presence $[A]$ or absence [a] of the amplified AFLP fragment (peak). The peak-absent marker phenotype is considered to be the homozygote genotype aa (whereas the peak-present marker phenotype corresponds to the genotypes $A a$ or $A A)$.

Distortion of segregation ratios

Segregation distortion analysis was performed using the chi-square goodness-of-fit statistical test between the $F_{1}$ parents and the $F_{2}$ progeny as detailed in Lallias et al. (2007b).

Power for detection of susceptibility genes in single and two-stage selection strategies

Two-stage selection strategy consists of 1 ) carrying out a Transmission Disequilibrium Test (TDT) on susceptible offspring to the disease and 2) testing only significant markers for susceptible and non-susceptible offspring by survival analysis. The advantage of twostage selection strategy versus one-stage testing is in the reduced genotyping cost. In this section we investigate how power is affected by using two versus one stage selection strategies. We assume dominant markers such as AFLPs. The susceptibility locus $(S, s)$ and the marker locus $(A, a)$ are assumed in full linkage disequilibrium. There are three possible parents: a) homozygotes for the locus for susceptibility to the disease and banded (SA/SA), b) heterozygotes for the locus for susceptibility to the disease and banded (SA/sa), and c) homozygotes for the locus for non-susceptibility (or resistance) to the disease and not banded (sa/sa). This gives three possible mating types with at least one segregating parent in the full family: 1) $S A /$ sa $\times S A / S A$, 2) $S A / s a \times S A / s a$ and, 3) $S A / s a \times$ sa/sa. Matings SA/sa $\times$ SA/SA and SA/sa $\times$ sa/sa correspond to type 1:1 segregations, whereas $S A$ /sa $x$ SA/sa corresponds to type 3:1 segregation. However, the mating type $S A / s a \times S A / S A$ led to offspring that were all banded and therefore not segregating. Therefore, only two mating types were considered: $S A / s a \times$ sa/sa and $S A / s a \times S A / s a$. To simplify the marker alleles are removed giving Ss $x$ ss and Ss $x$ Ss. We define $\Psi_{S S}, \Psi_{S s}$, and $\Psi_{s s}$ as the probabilities of developing the disease when animals have genotype SS, Ss, and SS, respectively. These are equivalent to "penetrance", used for hereditary diseases (Ott 1999). This parameter ( $\Psi$ ) is used to account for genes other than $S / s$ that may influence the disease. Table 1 illustrates the probabilities of inheritance of alleles linked to susceptibility to the disease for all three mating types. 
Power and expected rate of false positives in single stage detection of susceptibility loci: In order to compute power, a $\chi^{2}$ test for contingency tables was modeled Cohen 1988. Power in single stage detection of susceptibility loci was noted $P_{1, \alpha}$ (Appendix A). Power for detection of multiple susceptibility loci $\left(n_{1}\right)$ under multiple testing of $m$ markers (each marker represents one test) is given by $\boldsymbol{P}^{A}=\left(\boldsymbol{P}_{1, \alpha}\right)^{n_{l}}$, which assumes that probability of detection is independent for each tested locus, and therefore, susceptibility loci are not linked. The corresponding expected number of false positives is $\boldsymbol{E F P}^{A}=\alpha\left(\boldsymbol{m}-\boldsymbol{n}_{l}\right)$. The aim of a sound experimental design is to cover as much as possible of the genome with the highest $P^{A}$ and the lowest $E F P^{A}$.

Power and expected rate of false positives in two- stage detection of susceptibility loci: Moen et al. (2004) proposed a two-stage selection strategy based on first stage detection using only TDT with susceptible animals and second stage detection using all animals (susceptible and non-susceptible) and a survival analysis. TDT (Spielman et al. 1993) compares the number of times that a marker allele is transmitted or not transmitted from a heterozygous parent to an affected offspring, and therefore only the affected offspring are considered. Their strategy also required a Mendelian segregation test to avoid markers that are not inherited in a Mendelian fashion. Use of the normal approximation to the binomial distribution was used to compute power for a transmission disequilibrium test (TDT), $P_{T D T}$ (Appendix B). Power for detection of multiple susceptibility loci and expected number of false positives are $\boldsymbol{P}^{\boldsymbol{B 1}}=\left(\boldsymbol{P}_{T D T, \alpha}\right)^{\boldsymbol{n}_{l}}$ and $\boldsymbol{E F P} \boldsymbol{P}^{B 1}=\alpha\left(\boldsymbol{m}-n_{l}\right)$.

Only significant markers will be tested in the second stage. It is assumed that tests in the two stages are fully independent of each other. Power in second stage was computed using the same formulae as for single stage selection (with performance for all animals). The overall power of detection in two-stage strategy for detection of multiple susceptibility loci is $P^{B}=P^{B 1} P^{A}$. The expected number of false positives is $E F P^{B}=\alpha^{2}\left(m-n_{l}\right)$, which assumes that the same significant level, $\alpha$, is used in either testing stage.

From the above formulae it can be observed that (1) power is always greater for single stage testing but at a higher rate of false positives; (2) TDT depends on the transmission parameters and therefore, may yield non significant results for dominant susceptibility loci. A transmission parameter $(v)$ is the probability of transmission of one of the parental alleles to its offspring. For example in mating type Ss $x$ ss, if the probability of susceptibility to the disease is the same for carriers of either one or two copies of the $S$ allele then $v_{\text {Sxxs }}=1 / 2$ as it is under the null hypothesis, and 3) The expected rate of false positives is always smaller for two-stage selection strategies, as proposed by Moen et al. (2004).

We computed power at significance level $\alpha=0.05$ in one and two-stage QTL detection strategies and for all loci having $\Psi_{\mathrm{SS}}=0.70, \Psi_{\mathrm{Ss}}=0.25$, and $\Psi_{\mathrm{sS}}=0.05$. Note that with the relative small family size, linkage disequilibrium between alleles at the eight loci would be expected for those significant markers. The number of offspring used was 92 for single-stage detection of susceptibility loci, and 46 for the transmission disequilibrium test. Additionally, we computed power for single stage detection of susceptibility loci using the Bonferroni correction so the significance level became $\alpha / \#$ tests. The total number of markers tested was either 100 or 200 for each QTL detection strategy type. 
QTL analysis

Firstly, a two-stage testing strategy was performed AFLP marker by AFLP marker to identify potential QTLs, as described in Moen et al. (2004). A transmission disequilibrium test (TDT) was applied on the 46 affected offspring (oysters that died heavily infected with the parasite) for all the AFLP markers segregating in that family. A Mendelian segregation test (MST, test of Mendelian inheritance using all offspring) was applied to the whole dataset (affected and non-affected offspring) on markers significant after the TDT. The second test was the survival analysis itself. Survival analysis is used to describe and compare the survival times of two or more groups. Only markers that were significant after the TDT and not significant after the MST were kept for the survival analysis. Survival of two groups of offspring was compared: offspring with the peakpresent marker phenotype and offspring with the peak-absent marker phenotype. With the Kaplan-Meier method, survival is recalculated every time a member of the group dies. To calculate the fraction of individuals who survived on a particular day, the number alive at the end of the day is divided by the number alive at the beginning of the day. Kaplan-Meier survival curves were constructed for both groups and the hazard ratio (h) computed as described in Moen et al. (2004).

Secondly, a genetic linkage map was built for the F2 family with CriMap software as described in Lallias et al. (2007b). All microsatellites, all AFLPs of type 1:1 and the Mendelian 3:1 AFLPs were considered for linkage analysis. Two parental maps were constructed, one for each $\mathrm{F}_{1}$ parent.

Finally, a QTL mapping approach was performed with the QTL express software (Seaton et al. 2002) (http://qtl.cap.ed.ac.uk). In our study, one fixed effect was tested: raceway in which the oysters were kept (5 different raceways) and one covariate: total length at the time of death (in $\mathrm{cm}$ ). The trait analyzed was binary: the oysters that survived the challenge experiment were coded " 0 " and the ones that died during the challenge experiment were coded "1". The module "Large Single Full-Sib Family Analysis (Tree)" was chosen because it is designed for the case of a family with two parents that are not assumed to come from a cross between two distinct and different genetic lines. The analysis makes a comparison between the two gametes carried by the male parent (the paternal component) and the two gametes carried by the female parent (the maternal component). The finding of QTL used a regression interval mapping approach (Haley and Knott 1992). Chromosome-wide significance threshold (which takes into account multiple testing on a specific chromosome) was estimated after performing 1000 permutations according to Churchill and Doerge (1994). Separate analyses were performed for each $F_{1}$ parent, using the parent-specific maps established with CriMap. For the parent 410_7, the "pat" model was used to fit the paternal component and to find QTL. For the parent 410_8, the "mat" model was used to fit the maternal component and to find QTL. The paternal component relating to 410_7 and the maternal component to 410_8 were arbitrary (sex of the parental oysters unknown).

\section{Results}

Power for detection of susceptibility genes in single and two-stage selection strategies

Power for detection of susceptibility genes in one and two-stage selection strategies are given in Table 2. For the offspring size of 92, power to detect multiple susceptibility loci was rather high (between 0.93 and 1 ) irrespectively of the mating type. Power in the two- 
stage detection strategy was high, but marginally lower than power in one stage detection for all mating types.

The expected number of false positives for each type of mating is given in Table 3. As expected, single stage detection had the highest number of false positives. For one true susceptibility locus and 200 markers (tests), the number of false positives was high $(\sim 10)$. Bonferroni correction had the lowest number of false positives. The two-stage detection strategy had also very small expected number of false positives.

Survival analysis and the search for potential QTL of resistance/susceptibility to bonamiosis

The 34 AFLP primer pairs produced 309 markers, 201 AFLPs of type 1:1 (peak present in only one of the two parents) and 108 of type 3:1 (peak present in both parents). After the TDT, 144 markers were significant and kept for the MST: 83 of type 1:1 (22 with $\mathrm{p}<0.05 ; 20$ with $\mathrm{p}<0.01 ; 41$ with $\mathrm{p}<0.001)$ and 61 of type $3: 1$ (16 with $\mathrm{p}<0.05$; 18 with $\mathrm{p}<0.01 ; 27$ with $\mathrm{p}<0.001)$. Of the 144 markers significant after the TDT, only 26 were not significant after the MST: five markers segregated through the parent 410_7 (1:1 type), 10 through the parent 410_8 (1:1 type) and 11 through both parents (3:1 type) (Table 4).

Of the 26 markers kept for survival analysis, 15 were significant (four with $p<0.05$, two with $p<0.01$ and nine with $p<0.001$ ). The peak-present marker phenotype corresponded to a resistance allele in nine cases and to a susceptible allele in six cases. Hazard ratios were in the range 0.24-0.45: inheriting the peak-present allele reduced (or increased) the mortality by $\sim 24 \%$ to $45 \%$ for a resistant (or susceptible) marker (Table 5). Kaplan-Meier survival curves were constructed for the markers with $p<0.01$, these were eight AFLPs $(p<0.01)$ for which the peak-present phenotype corresponded to a resistant allele (Figure 1$)$ and three AFLPs $(p<0.01)$ for which the peak-present phenotype corresponded to a susceptible allele (Figure 2).

Genetic linkage mapping

Overall, $25 \%$ of the markers were distorted, $47.4 \%$ of the microsatellites (9 out of 19) and $23.6 \%$ of the AFLPs (73 out of 309 ).

The 410_7 parental genetic linkage map was based on the 17 microsatellites that were informative for this parent and 157 AFLPs segregating through this parent. The AFLPs consisted of 112 markers of type 1:1 (43 from 98AC703-29, 55 from W31 and 14 from both grand-parents) and 45 markers of type 3:1 (29 from 98AC703-29 and 16 from W31). The resulting map consisted of 127 markers (73.0\%), comprising 16 microsatellites (of 17: 94.1\%), 94 type 1:1 AFLPs (of 112: 83.9\%), 17 type 3:1 AFLPs (of 45: 37.8\%). Ten linkage groups were established for the 410_7 map covering $465.6 \mathrm{cM}$ (Figure 3). The estimated genome length was $553.37 \mathrm{cM}$ according to method 4 of Chakravarti et al. (1991). The observed coverage was therefore $84.1 \%$ for the 410_7 parental map. Features of the genetic linkage map are shown in Table 6. Distorted markers tended to cluster in specific linkage groups (LG3_410_7, LG4_410_7, LG7_410_7, LG8_410_7, LG9_410_7 and LG10_410_7).

The 410_8 parental genetic linkage map was based on the 18 microsatellites that were informative for this parent and 124 AFLPs segregating through this parent. The AFLPs consisted of 79 markers of type 1:1 (31 from 98AC703-29, 39 from W31 and 9 from both grand-parents) and 45 markers of type 3:1 (29 from 98AC703-29 and 16 from W31). The resulting map consisted of 98 markers (70.0\%), comprising 14 microsatellites (of 18: 77.8\%), 71 type 1:1 AFLPs (of 79: 89.9\%), 13 type 3:1 AFLPs (of 45: 28.9\%). Ten linkage groups were established for the 410_8 map covering 386.7 cM (Figure 4). The 
estimated genome length was $556.91 \mathrm{cM}$. The observed coverage was therefore $69.4 \%$ for the 410_8 map. Features of the genetic linkage map are shown in Table 7. Distorted markers towards a deficit $(-)$ or excess $(+)$ in aa homozygotes could be mapped on 6 different linkage groups: LG1_410_8, LG3_410_8, LG4_410_8, LG6_410_8, LG8_410_8 and LG10_410_8. Generally, distorted markers in the same direction and with the same level of statistical significance tended to cluster and to be mapped over a very short distance (e.g. 2 or 3 (+) markers in LG1_410_8, LG6_410_8, LG8_410_8 or LG10_410_8; 4 (-) markers in LG3_410_8).

Of the seven markers that remained significant after the survival analysis and that segregated through the parent 410_7, four could be mapped on the 410_7 map, three resistant markers and one susceptible marker: D1f203 on LG2_410_7; E3f255, E1f43 and A12f429 on LG4_410_7. The three markers on LG4_410_7 were mapped in a $14 \mathrm{cM}$ area and interestingly they have the same grand-parental origin (98AC703-29), while the fourth marker (D1f203) mapped in another linkage group came from the second grand-parent (W31) (Figure 3).

For the 410_8 parent, of the 15 markers significant after the survival analysis, 12 of those could be mapped on the 410_8 map, eight resistant markers and four susceptible markers. These 12 markers were distributed on four linkage groups: D1f203 on LG2_410_8; E5f157, A3f73 and A1f150 on LG3_410_8; E1f43, E3f255 and A12f429 on LG4_410_8; D1f328, E3f169, E9f368, B12f243 and C1f99 on LG6_410_8. The three markers on LG3_410_8 mapped in a $9 \mathrm{cM}$ area; the markers on LG4_410_8 clustered altogether and the five markers on LG6_410_8 mapped in a $18 \mathrm{cM}$ area. Moreover, it is interesting to note that resistant markers on the same linkage group came from the same grand-parent while the susceptible markers came from the other grand-parent (LG3_410_8 and LG6_410_8) (Figure 4).

We also compared the mapping of the markers that were significant after the survival analysis in the two parental maps. The marker D1f203 mapped in the two parental maps at the same end of the linkage groups (LG2_410_8 and LG2_410_7), very close to microsatellite OeduU2. Moreover, the three markers E1f43, E3f255 and A12f429 were mapped in the two parental maps, in the terminal part of the linkage groups: they were clustered at the end of group LG4_410_8, while in LG4_410_7 they were mapped in a $14 \mathrm{cM}$ terminal area with two of them being clustered (E1f43 and A12f429).

QTL mapping

No significant effects were found for the fixed effect (raceway) or the covariate (length of oyster at the time of death). Consequently, they were not included in the QTL model.

For the 410_7 parent, four linkage groups exhibited a significant paternal estimate, meaning that the two different gametes carried alleles of different effect for the QTL. The best estimate of location for the QTL was $0 \mathrm{cM}$ for LG2-410_7, $0 \mathrm{cM}$ for LG3_410_7, $24 \mathrm{cM}$ for LG4_410_7 and $8 \mathrm{cM}$ for LG6_410_7. Only linkage group LG2_410_7 attained significance at the chromosome-wide 0.01 level. The two linkage groups LG4_410_7 and LG6_410_7 attained significance at the chromosome-wide 0.05 level, but only just (Table 8).

For the 410_8 parent, two linkage groups exhibited a significant maternal estimate. The best estimate of location for the QTL was 61 cM for LG3_410_8 and 17 CM for LG6_410_8. Linkage group LG3_410_8 attained significance at the chromosomewide 0.05 level, and LG6_410_8 at the chromosome-wide 0.01 level (Table 9). 


\section{Discussion}

\section{Segregation distortion}

Relatively high segregation distortion was reported in the mapping family OE.F2.05.04, averaging $25 \%$ of overall markers. The range of segregation distortion reported in this study was similar to that reported in oysters (Launey and Hedgecock 2001; Li and Guo 2004; Lallias et al. 2007b). Such a high level of segregation distortion is presumed to be due to the extremely high genetic load estimated in oysters (Bierne et al. 1998; Launey and Hedgecock 2001). Moreover, the distribution of distorted markers was not random in the genetic linkage maps produced and tended to form clusters of distorted markers that were restricted to a few linkage groups (e.g. LG3_410_7, LG8_410_7 or LG3_410_8; Figures 3 and 4). These clusters of distorted markers could therefore correspond to the location of potential deleterious genes in $O$. edulis, similarly to the mapping of potential deleterious genes in the rainbow trout (Young et al. 1998) or the Pacific oyster C. gigas (Li and Guo 2004).

In the second stage of the two-stage selection strategy (Moen et al. 2004), we excluded markers departing from Mendelian segregation in the first stage. Distortion may be caused by recessive lethal genes at larval stages (Bierne et al. 1998), which may include susceptibility to bonamiosis. Null alleles and other problems can also lead to such departures from Mendelian segregation. Therefore, those markers were ignored in the second stage analyses because it is very difficult with the available data to figure out the causes underlying the observed departures from Mendelian segregation.

Linkage map and genome coverage

Genome coverage was above $82 \%$ for the $410 \_7$ parental map, and $69.4 \%$ for the 410_8 parental map. Those genome coverage estimates compared favorably with the ones established in cupped and flat oysters' species which were in the range of $70-90 \%$ depending on the study (Hubert and Hedgecock 2004; Li and Guo 2004; Lallias et al. 2007b).

Moreover, the number of linkage groups in the two parental maps matched the haploid number of 10 chromosomes in this species (Thiriot-Quiévreux and Ayraud 1982). However, more markers should be added to increase the genome coverage. Indeed, some of the linkage groups consisted of only two markers or spanned a small genetic distance $(<20 \mathrm{cM})$. Therefore, these groups may in fact belong to the same chromosome and may fuse by adding more markers. Despite this, the average marker spacing (4cM) was suitable for the search of QTL (Erickson et al. 2004).

\section{QTL mapping of resistance/susceptibility to a disease}

Several studies have highlighted the potential for MAS in breeding programs in fisheries and probably shellfisheries in the future (Liu and Cordes 2004; Rothschild and Ruvinsky 2007). MAS has a huge potential in aquaculture breeding programs, especially for traits that are difficult to quantify phenotypically and would increase the response of the trait to the selection by increasing the accuracy of selection.

Although disease resistance generally seems to have a low heritability in some species it is nevertheless an ideal trait for the application of MAS, due to the economic significance of high survival in aquaculture. Traditionally, the QTL mapping approach was designed for continuously variable quantitative traits. However, it has been shown 
that this analysis is robust for binary traits, such as resistance/susceptibility to a disease (death/alive trait coded as "0" or "1") (Visscher et al. 1996). Therefore, we decided to couple the marker by marker approach with a traditional QTL mapping approach in order to compare the results obtained with these two alternative approaches. The finding of QTL was achieved by using a two-stage testing strategy (Moen et al. 2004) and a regression interval mapping approach (QTL express software, Seaton et al. 2002).

Statistic power of the two-stage testing strategy and rate of false positives were computed by simulations. Power calculations were carried out assuming that multiple QTL are unlinked. If two QTL are closely linked and the alleles increasing susceptibility are on the same homologous chromosome in a parent donating meiosis then the power calculation would be similar to one QTL with increased penetrance respect to either single QTL. The opposite would occur when alleles at two QTL with high and low penetrances are on the same homologous chromosome. On the other hand, the twostage testing strategy assumed that TDT performed on susceptible animals and the survival analyses used on the whole data set are independent tests. This assumption is not fully correct, since there may be some dependence between the variables used (affected/resistant and number of days survived). As pointed out by Moen et al. (2004), this assumption is supported by the fact that animals tested in the TDT are only a subset of the animals tested in the survival analysis.

False negatives are missing true linkages whereas false positives are false linkage claims. Mapping in genome scans should minimize both. For the two-stage strategy a total of 309 markers were tested with 9 significant results at $P<0.001$ after the survival analyses. This implies than in average less than one of the significant results is spurious (false positive). False negatives would be given by the type I error and would also be less than one for the 309 markers.

Power for detection of multiple susceptibility loci in single stage detection was the highest at the expense of a high rate of false positives. The use of a Bonferroni correction to control the false positive rate resulted in a dramatic reduction of power for some mating types when detecting multiple susceptibility loci. The two-stage detection strategy had a high power with a low rate of false positives (Tables 2,3 ). The two-stage testing strategy was a powerful and robust method for identifying QTL of resistance/susceptibility to a disease and allowed us to identify 15 probable AFLP markers linked to genes of resistance (nine of them) or susceptibility (six of them) to the disease. Considering all the above, the two-stage selection strategy might be useful in aquaculture species with high family sizes and incomplete genetic maps.

The QTL mapping approach chosen was a regression interval mapping (interval mapping based on least-squares regression methods) (Haley and Knott 1992). Indeed, an interval mapping approach is based on information from two linked flanking markers and has been shown to be more powerful than a single marker analysis particularly for medium-density maps (with markers around 20-35 cM apart) and to increase the accuracy of parameters estimation (Darvasi et al. 1993). The analysis was based on a single full-sib family experimental design (and not a $F_{2}$ analysis) because the mapping family was a three-generation outbred family whose grand-parents were not issued from different genetic lines fixed for different alleles at the QTL. The analysis was interpreted in terms of paternal and maternal components, i.e. whether the two gametes of each parent carried alleles of different effect for the QTL. However, no estimation of the interaction component (and therefore dominance of the QTL) could be performed because of the lack of codominant loci (e.g. microsatellites). Furthermore, a consensus map could not be built because most markers were segregating in only one of the two parents and the estimation of the interaction component implies that the map is the same in the two parents. Moreover, because only 92 progeny were genotyped, a one- 
QTL model was fitted but not a two-QTL model. The results obtained after fitting the oneQTL model should be interpreted with caution because the role of neighbouring QTL in biasing the estimation of location and gene effect of a QTL has been widely assessed (Haley and Knott 1992; Jansen 1993). The results of the one-QTL model can be misleading when there are in fact two linked QTL segregating on the same linkage group.

Despite some limitations, our study has made major progress towards the identification of genetic resistance/susceptibility to bonamiosis. Several potential markers of interest were identified and there was good concordance between the results obtained after the two-stage testing strategy, genetic mapping and QTL mapping. Identified markers tended to cluster or were restricted to a few groups: in the 410_7 map, three markers were mapped in a 15 cM area in LG4_410_7 group and a fourth marker was mapped in LG2_410_7 group (Figure 3); in the 410_8 map, three markers were mapped in a $9 \mathrm{cM}$ area in LG3_410_8, five markers were mapped in a $17 \mathrm{cM}$ area in LG6_410_8, three markers were clustered at the end of LG4_410_8 and one marker was mapped in LG2_410_8 (Figure 4). Moreover, the significant QTL found after the regression interval mapping approach were mapped in the same area as the markers that were significant after the survival analysis. Therefore, this study clearly demonstrates for the first time the usefulness of combining different approaches for the search of QTL in aquaculture species, associated with a high statistical power.

Hazard ratios in this study were very high, with single alleles inheritance affecting survival of the offspring bearing it by as much as 24 to $45 \%$. We may wonder how such variation can be maintained against purifying selection. The effects may vary between families for the same alleles and their related causal genes, due to different genetic backgrounds and non-additive effects. Important G x E (Genotype x Environment) interactions might also occur. Therefore QTL analysis in a single family is limiting and QTL analysis should be extended to several families in order to test these hypotheses.

Several studies have reported the location of QTL for disease resistance in rainbow trout, based on the classical approach for QTL mapping using interval mapping, the ANOVA-based approach, or Bulk Segregant Analysis (BSA) (e.g. Ozaki et al. 2001; Rodriguez et al. 2004). The results obtained in this study, even if preliminary, are promising and represent a first step towards MAS in the flat oyster. However, before implementation of MAS in a selective breeding program, the role of epistasis and genomic background should be assessed (Danzmann et al. 1999; Perry et al. 2003). Moreover, screening natural populations for outlier levels of differentiation at QTL loci (Rogers and Bernatchez 2005) could add value in terms of robustness and universality of the QTL identified. The QTL identified could be scored in wild and selected populations. One should expect an average increase in gene frequencies of QTL markers for resistance in the selected populations and a respective decrease in the QTL for susceptibility to the disease.

The addition of codominant markers (such as microsatellites or SNPs) is critical to increase the accuracy of the genetic maps obtained, the power of detection of the QTL and the accuracy of the estimation of the QTL effects. Moreover, before implementation of MAS in O. edulis, fine QTL mapping should be achieved in order to restrict the region of interest to a more narrow area. A further step would be to map candidate genes involved in the resistance to the disease that were recently identified after performing a SSH (Suppression Subtractive Hybridisation) library (Morga et al. in prep). This would help to corroborate QTL with candidate genes and would represent a further step into the understanding of the genetic component of the resistance/susceptibility of $O$. edulis to $B$. ostreae. 


\section{References}

Bédier E, Cochennec-Laureau N, Langlade A, Kopp J, Goyard E, Gérard A (2001) Recovery of the European flat oyster Ostrea edulis (L.): new development. Proceedings of the European Aquaculture Society annual meeting 2001

Bierne N, Launey S, Naciri-Graven Y, Bonhomme F (1998) Early effect of inbreeding as revealed by microsatellite analyses on Ostrea edulis larvae. Genetics 148:1893-1906

Cavalier-Smith T, Chao EE (2003) Phylogeny and classification of phylum Cercozoa (Protozoa). Protist 154:341-358

Chakravarti A, Lasher LK, Reefer JE (1991) A maximum likelihood method for estimating genome length using genetic linkage data. Genetics 128:175-182

Churchill GA, Doerge RW (1994) Empirical threshold values for quantitative trait mapping. Genetics 138:963-971

Cochennec N, Le Roux F, Berthe F, Gérard A (2000) Detection of Bonamia ostreae Based on Small Subunit Ribosomal Probe. J Invertebr Pathol 76:26-32

Cohen J (1988). Statistical Power Analysis for the Behavioral Sciences. Lawrence Erlbaum Associates, Hillsdale, N.J.

Culloty SC, Cronin MA, Mulcahy MF (2004) Potential resistance of a number of populations of the oyster Ostrea edulis to the parasite Bonamia ostreae. Aquaculture 237:41-58

Danzmann RG, Jackson TR, M. Ferguson M (1999) Epistasis in allelic expression at upper temperature tolerance QTL in rainbow trout. Aquaculture 173:45-58

Darvasi A, Weinreb A, Minke V, Weller JI, Soller M (1993) Detecting marker-QTL linkage and estimating QTL gene effect and map location using a saturated genetic map. Genetics 134:943-951

Erickson DL, Fenster CB, Stenoien HK, Price D (2004) Quantitative trait locus analyses and the study of evolutionary process. Mol Ecol 13:2505-2522

Gomez-Raya L (2001) Biased estimation of the recombination fraction using half-sib families and informative offspring. Genetics 157:1357-1367

Haley CS, Knott SA (1992) A simple regression method for mapping quantitative trait loci in line crosses using flanking markers. Heredity 69:315-324

Hubert S, Hedgecock D (2004) Linkage maps of microsatellite DNA markers for the Pacific oyster Crassostrea gigas. Genetics 168:351-362

Jansen RC (1993) Interval mapping of multiple quantitative trait loci. Genetics 135:205211

Lallias D, Lapègue S, Hecquet C, Boudry P, Beaumont AR (2007a) AFLP-based genetic linkage maps of the blue mussel (Mytilus edulis). Anim Genet 38:340-349

Lallias D, Beaumont AR, Haley CS, Boudry P, Heurtebise S, Lapègue S (2007b) A firstgeneration genetic linkage map of the European flat oyster Ostrea edulis (L.) based on AFLP and microsatellite markers. Anim Genet 38:560-568

Lallias D, Arzul I, Heurtebise S, Ferrand S, Chollet B, Robert M, Beaumont AR, Boudry $P$, Morga $B$, Lapègue $S$ (2008) Bonamia ostreae-induced mortalities in one-year old European flat oysters Ostrea edulis: experimental infection by cohabitation challenge. Aquat Living Resour 21:423-439

Launey S, Hedgecock D (2001) High genetic load in the Pacific oyster Crassostrea gigas. Genetics 159:255-265

Launey S, Ledu C, Boudry P, Bonhomme F, Naciri-Graven Y (2002) Geographic structure in the European flat oyster (Ostrea edulis L.) as revealed by Microsatellite polymorphism. J Hered 93:331-351 
Li L, Guo X (2004) AFLP-based genetic linkage maps of the pacific oyster Crassostrea gigas Thunberg. Mar Biotechnol 6:26-36

Li L, Xiang J, Liu X, Zhang Y, Dong B, Zhang X (2005) Construction of AFLP-based genetic linkage map for Zhikong scallop, Chlamys farreri Jones et Preston and mapping of sex-linked markers. Aquaculture 245:63-73

Liu ZJ, Cordes JF (2004) DNA marker technologies and their applications in aquaculture genetics. Aquaculture 238:1-37

Moen T, Fjalestad KT, Munck H, Gomez-Raya L (2004) A multistage testing strategy for detection of quantitative trait Loci affecting disease resistance in Atlantic salmon. Genetics 167:851-858

Morgan TS, Rogers AD (2001) Specificity and sensitivity of microsatellite markers for the identification of larvae. Mar Biol 139:967-973

Morgan TS, Rogers AD, lyengar A (2000) Novel microsatellite markers for the European oyster Ostrea edulis. Mol Ecol 9:495-497

Naciri-Graven Y, Martin A-G, Baud J-P, Renault T, Gerard A (1998) Selecting the flat oyster Ostrea edulis (L.) for survival when infected with the parasite Bonamia ostreae. J Exp Mar Biol Ecol 224:91-107

Naciri Y, Vigouroux Y, Dallas J, Desmarais E, Delsert C, Bonhomme F (1995) Identification and inheritance of (GA/TC)n and (AC/GT)n repeats in the European flat oyster Ostrea edulis (L.). Mol Mar Biol Biotechnol 4:83-89

Ott J (1999). Analysis of Human Genetic Linkage. Johns Hopkins University Press, Baltimore.

Ozaki A, Sakamoto T, Khoo S, Nakamura K, Coimbra MR, Akutsu T, Okamoto N (2001) Quantitative trait loci (QTLs) associated with resistance/susceptibility to infectious pancreatic necrosis virus (IPNV) in rainbow trout (Oncorhynchus mykiss). Mol Genet Genomics 265:23-31

Perry GM, Ferguson MM, Danzmann RG (2003) Effects of genetic sex and genomic background on epistasis in rainbow trout (Oncorhynchus mykiss). Genetica 119:35-50

Ruesink JL, Lenihan HS, Trimble AC, Heiman KW, Micheli F, Byers JE, Kay MC (2005) Introduction of non-native oysters: Ecosystem effects and restoration implications. Ann Rev Ecol Evol Syst 36:643-689

Rodriguez MF, LaPatra S, Williams S, Famula T, May B (2004) Genetic markers associated with resistance to infectious hematopoietic necrosis in rainbow and steelhead trout (Oncorhynchus mykiss) backcrosses. Aquaculture 241:93-115

Rogers M, Bernatchez L (2005) Integrating QTL mapping and genome scans towards the characterization of candidate loci under parallel selection in the lake whitefish (Coregonus clupeaformis). Mol Ecol 14:351-361.

Rothschild MF, Ruvinsky A (2007) Marker-assisted selection in aquaculture species. In: Liu, Z. (Ed.), Aquaculture Genome Technologies. Blackwell Publishing, pp. 199-213.

Sambrook J, Fritsch EF, Maniatis T (1989) Molecular cloning: A laboratory manual. Cold Spring Harbor Laboratory Press.

Seaton G, Haley CS, Knott SA, Kearsey M, Visscher PM (2002) QTL Express: mapping quantitative trait loci in simple and complex pedigrees. Bioinformatics 18:339-340

Sobolewska H, Beaumont AR, Hamilton A (2001) Dinucleotide microsatellites isolated from the European flat oyster, Ostrea edulis. Mol Ecol Notes 1:79-80

Spielman RS, McGinnis RE, Ewens WJ (1993) Transmission test for linkage disequilibrium: the insulin gene region and insulin-dependent diabetes mellitus (IDDM). Am J Hum Genet 52:506-516

Thiriot-Quiévreux C, Ayraud N (1982) Les caryotypes de quelques espèces de bivalves et de gastéropodes marins Mar Biol 70:165-172 
Visscher PM, Haley CS, Knott SA (1996) Mapping QTLs for binary traits in backcross and F2 populations. Genet Res 68:55-63

Vos $\mathrm{P}$, Hogers R, Bleeker M, Reijans $M$, van de Lee T, Hornes M, Frijters A, Pot J, Peleman J, Kuiper M, Zabeau M (1995) AFLP: a new technique for DNA fingerprinting. Nucleic Acids Res 23:4407-4414

Young WP, Wheeler PA, Coryell VH, Keim P, Thorgaard GH (1998) A detailed linkage map of rainbow trout produced using doubled haploids. Genetics 148:839-850

Yu Z, Guo X (2006) Identification and mapping of disease-resistance QTLs in the eastern oyster, Crassostrea virginica Gmelin. Aquaculture 254:160-170

Appendix A Power in single stage detection of susceptibility loci

In order to compute power, a $\chi^{2}$ test for contingency tables was modeled Cohen 1988. There are four types of offspring possible for each type of mating (Table 1): 1) banded and with the disease, 2) banded without the disease, 3) not banded and with the disease, and 4) not banded without the disease. Under the null hypothesis (the AFLP locus is not linked to the susceptibility locus), $\Psi_{S s}=\Psi_{S s}=\Psi_{s s}=1 / 2$. Let $t_{\alpha}$ be the value in a $\chi^{2}$ test with 1 degree of freedom equal or higher than for expected by chance at significance level $(\alpha)$. Power is $P_{1, \alpha}=1-\beta$ with $\beta=\int_{t_{\alpha}}^{\infty} f(x) d x$, being $f_{x} \sim \chi^{2}(\lambda$, df), where $\lambda$ is the non-centrality parameter of a non central $\chi^{2}$ distribution with $\mathrm{df}=1$ degrees of freedom. The non- central parameter of the $\chi^{2}$ distribution is

$\lambda=N \sum_{i=1}^{4} \frac{\left[p_{0}(i)-p_{A}(i)\right]^{2}}{p_{o}(i)}$

where $\mathrm{N}$ is the total number of individuals in the experiment, $p_{0}(i)$ and $p_{A}(i)$ are the probabilities of each type of offspring ( $\mathrm{i}=1$ to 4$)$ under the null and alternative hypothesis respectively. For the mating type Ss $x$ ss: $p_{0}(i)=1 / 4(i=1,4) ; p_{A}(1)=1 / 2 \Psi_{S s} ; p_{A}(2)=1 / 2(1-$ $\left.\Psi_{S S}\right) ; p_{A}(3)=1 / 2 \Psi_{S S} ;$ and $p_{A}(4)=1 / 2\left(1-\Psi_{S S}\right)$. For the mating type Ss $x$ Ss: $p_{0}(1)=3 / 8, p_{0}(2)=$ $3 / 8, p_{0}(3)=1 / 8$, and $p_{0}(4)=1 / 8 ; p_{A}(1)=1 / 4 \Psi_{S S}+1 / 2 \Psi_{S s} ; p_{A}(2)=1 / 4\left(3-\Psi_{S S}+2 \Psi_{S S}\right) ; p_{A}(3)=1 / 4 \Psi_{S S} ;$ and $p_{A}(4)=1 / 4\left(1-\Psi_{S S}\right)$.

Appendix B Power in two-stage detection of susceptibility loci

Under the null hypothesis (the AFLP is not linked to the susceptibility locus), for a sire Ss, the probability of transmission of the allele $S$ and being banded is $1 / 2$ and $3 / 4$ for segregation of mating types $1: 1$ and 3:1, respectively. At a significance level of $\alpha=0.05$, the maximum number of offspring inheriting one of the markers alleles by chance is $N x=\frac{n+1.96 \sqrt{n}}{2}$ and $N x=\frac{3 n+1.96 \sqrt{3 n}}{4}$. In the above formula, $\mathrm{n}$ is the number of offspring in the full sib family used for TDT test, and therefore, $n=N / 2$. This is a two sided probability to account that either marker allele could be inherited in a distorted fashion. Under the alternative hypothesis, we assume that the distorted frequency of segregation of marker alleles is the transmission disequilibrium parameter, v Gomez-Raya 2001. This parameter has different values for the different mating types: 


$$
\begin{aligned}
& v_{S s x S s}=\frac{\frac{\mathbf{1}}{\mathbf{4}} \psi_{S S}+\frac{\mathbf{1}}{\mathbf{2}} \psi_{S s}}{\frac{\mathbf{1}}{\mathbf{4}} \psi_{S s}+\frac{\mathbf{1}}{\mathbf{2}} \psi_{S s}+\frac{\mathbf{1}}{\mathbf{4}} \psi_{s s}}, \\
& v_{S s x s s}=\frac{\frac{\mathbf{1}}{\mathbf{2}} \psi_{S s}}{\frac{\mathbf{1}}{\mathbf{2}} \psi_{S s}+\frac{\mathbf{1}}{\mathbf{2}} \psi_{s s}}
\end{aligned}
$$

Transmission parameter $\boldsymbol{v}_{\text {Ssxss }}$ corresponds to segregation 1:1, whereas transmission parameter $\boldsymbol{v}_{\text {SsxSs }}$ corresponds to segregation 3:1. The probability of $\mathrm{Nx}$ or more individuals inheriting the given marker allele under $v$ is the power of the test:

$$
\begin{aligned}
& P_{T D T}=\int_{-z}^{\infty} f(x) d x \text {, where } f(x) \text { is the normal density, with } z=\frac{\frac{n+1.96 \sqrt{n}}{2}-n v}{\sqrt{n v(1-v)}} \text { and } \\
& z=\frac{\frac{3 n+1.96 \sqrt{3 n}}{4}-n v}{\sqrt{n v(1-v)}} \text { for mating with segregation types } 1: 1 \text {, and 3:1, respectively. }
\end{aligned}
$$

\section{Acknowledgements}

This research has been financed by the European Regional Development Fund INTERREG IIIB, project 091 - AAAG, and received the support of the Marine Genomics Europe Network of Excellence through a one-month fellowship (Gender Action Plan). The authors thank Sylvie Ferrand, Bruno Chollet, Maeva Robert and Benjamin Morga for their help and involvement during the cohabitation challenge experiment. CSH acknowledges support from the Biotechnology and Biological Sciences Research Council. The authors thank two anonymous referees for constructive comments on the manuscript.

\section{Tables}

Table 1 Probabilities of susceptible and non susceptible offspring with different genotypes for different types of mating Ss $x$ SS, Ss $x$ Ss, and Ss $x$ ss in a full sib family. $\Psi_{\mathrm{SS}}, \Psi_{\mathrm{Ss}}$, and $\Psi_{\mathrm{ss}}$ are the probabilities of developing the disease when animals have genotype SS, Ss, and ss, respectively. 


\begin{tabular}{|c|c|c|c|}
\hline \multirow[t]{2}{*}{ Mating } & \multirow[t]{2}{*}{ Offspring Genotype } & \multicolumn{2}{|l|}{ Probability } \\
\hline & & Susceptible & Non Susceptible \\
\hline \multirow[t]{4}{*}{ Ss $\times$ Ss } & SS & $1 / 4 \Psi_{S S}$ & $1 / 4\left(1-\Psi_{S S}\right)$ \\
\hline & Ss & $1 / 4 \Psi_{\mathrm{Ss}}$ & $1 / 4\left(1-\Psi_{S s}\right)$ \\
\hline & sS & $1 / 4 \Psi_{\mathrm{Ss}}$ & $1 / 4\left(1-\Psi_{S s}\right)$ \\
\hline & SS & $1 / 4 \Psi_{\mathrm{sS}}$ & $1 / 4\left(1-\Psi_{s S}\right)$ \\
\hline \multirow[t]{2}{*}{ Ss $\times$ SS } & Ss & $1 / 2 \Psi_{\mathrm{Ss}}$ & $1 / 2\left(1-\Psi_{S s}\right)$ \\
\hline & SS & $1 / 2 \Psi_{\mathrm{SS}}$ & $1 / 2\left(1-\Psi_{S S}\right)$ \\
\hline
\end{tabular}

Table 2 Power to detect multiple susceptibility loci in one or two-stage testing strategies. TRUE SL: number of true QTL segregating in the population ; $\alpha=$ significance level. $\Psi_{S S}=0.70 ; \Psi_{S s}=0.25 ; \Psi_{S S}=0.05$.

A)

B)

\begin{tabular}{llll}
\hline TRUE SL & \multicolumn{3}{l}{ Power. Mating type Ss $x$ Ss } \\
\cline { 2 - 4 } & $\begin{array}{l}\text { Single stage } \\
\alpha=0.05\end{array}$ & $\begin{array}{l}\text { Single stage } \\
\alpha=0.05 / 100\end{array}$ & $\begin{array}{l}\text { Two-stage } \\
\alpha=0.05\end{array}$ \\
\hline 8 & 0.9696 & 0.3396 & 0.9692 \\
7 & 0.9734 & 0.3887 & 0.9730 \\
6 & 0.9771 & 0.4449 & 0.9768 \\
5 & 0.9809 & 0.5092 & 0.9806 \\
4 & 0.9847 & 0.5828 & 0.9845 \\
3 & 0.9885 & 0.6670 & 0.9883 \\
2 & 0.9923 & 0.7634 & 0.9922 \\
1 & 0.9962 & 0.8737 & 0.9961 \\
\hline
\end{tabular}

\begin{tabular}{llll}
\hline TRUE SL & \multicolumn{3}{l}{ Power. Mating type Ss $x$ ss } \\
\cline { 2 - 4 } & $\begin{array}{l}\text { Single stage } \\
\alpha=0.05\end{array}$ & $\begin{array}{l}\text { Single stage } \\
\alpha=0.05 / 100\end{array}$ & $\begin{array}{l}\text { Two-stage } \\
\alpha=0.05\end{array}$ \\
\hline 8 & 1.0000 & 0.9982 & 0.9976 \\
7 & 1.0000 & 0.9984 & 0.9979 \\
6 & 1.0000 & 0.9986 & 0.9982 \\
5 & 1.0000 & 0.9988 & 0.9985 \\
4 & 1.0000 & 0.9991 & 0.9988 \\
3 & 1.0000 & 0.9993 & 0.9991 \\
2 & 1.0000 & 0.9995 & 0.9994 \\
1 & 1.0000 & 0.9998 & 0.9997 \\
\hline
\end{tabular}

Table 3 Expected number of false positives detected in one or two-stage QTL detection strategies. TRUE SL: number of true QTL segregating in the population; \# Tests: number of tests; $\alpha=$ significance level. $\Psi_{\mathrm{SS}}=0.70 ; \Psi_{\mathrm{Ss}}=0.25 ; \Psi_{\mathrm{SS}}=0.05$.

\begin{tabular}{llll} 
TRUE SL & Single stage & Single stage & Two-stage \\
$\alpha=0.05$ & $\alpha=0.05 / 100$ & $\alpha=0.05$ \\
\cline { 2 - 4 } & \# Tests & \# Tests & \# Tests
\end{tabular}




\begin{tabular}{lllllll} 
& 100 & 200 & 100 & 200 & 100 & 200 \\
\hline 8 & 4.60 & 9.60 & 0.05 & 0.10 & 0.23 & 0.48 \\
7 & 4.65 & 9.65 & 0.05 & 0.10 & 0.23 & 0.48 \\
6 & 4.70 & 9.70 & 0.05 & 0.10 & 0.24 & 0.49 \\
5 & 4.75 & 9.75 & 0.05 & 0.10 & 0.24 & 0.49 \\
4 & 4.80 & 9.80 & 0.05 & 0.10 & 0.24 & 0.49 \\
3 & 4.85 & 9.85 & 0.05 & 0.10 & 0.24 & 0.49 \\
2 & 4.90 & 9.90 & 0.05 & 0.10 & 0.25 & 0.50 \\
1 & 4.95 & 9.95 & 0.05 & 0.10 & 0.25 & 0.50 \\
\hline
\end{tabular}

Table 4 TDT and MST for the 26 markers that were kept for survival analysis (significant after TDT among susceptible progeny and non significant after MST in the whole progeny). present: band-present phenotype (Aa or A?), absent: band-absent phenotype (aa); TDT: transmission disequilibrium test; MST: Mendelian segregation test; *: $p<0.05$, $\star *$ : $p<0.01,{ }^{* * *}: p<0.001$.

\begin{tabular}{|c|c|c|c|c|c|c|c|c|}
\hline \multirow[t]{2}{*}{ Marker } & \multicolumn{2}{|c|}{ Parental genotypes } & \multicolumn{2}{|c|}{$\begin{array}{l}\text { No. of susceptible } \\
\text { offspring (dead) }\end{array}$} & \multicolumn{2}{|c|}{$\begin{array}{l}\text { No. of resistant } \\
\text { offspring (surviving) }\end{array}$} & \multirow[t]{2}{*}{ TDT } & \multirow[t]{2}{*}{ MST } \\
\hline & $410-7$ & $410-8$ & present & absent & present & absent & & \\
\hline A1f150 & aa & $\mathrm{Aa}$ & 33 & 12 & 21 & 25 & $9.8^{* *}$ & 3.1 \\
\hline E1f43 & $\mathrm{Aa}$ & $\mathrm{Aa}$ & 25 & 21 & 38 & 8 & $9.2^{* *}$ & 2.1 \\
\hline A3f73 & aa & $\mathrm{Aa}$ & 12 & 34 & 25 & 21 & $10.5^{\star \star}$ & 3.5 \\
\hline A3f165 & $\mathrm{Aa}$ & $\mathrm{Aa}$ & 42 & 4 & 35 & 11 & $8.1^{\star \star}$ & 3.7 \\
\hline E3f169 & aa & $\mathrm{Aa}$ & 10 & 36 & 27 & 19 & $14.7^{* \star \star}$ & 3.5 \\
\hline E3f255 & $\mathrm{Aa}$ & $\mathrm{Aa}$ & 25 & 21 & 38 & 8 & $9.2^{\star \star}$ & 2.1 \\
\hline E4f291 & $\mathrm{Aa}$ & aa & 16 & 30 & 23 & 23 & $4.3^{\star}$ & 2.1 \\
\hline A5f225 & aa & $\mathrm{Aa}$ & 16 & 30 & 21 & 25 & $4.3^{*}$ & 3.5 \\
\hline E5f126 & $\mathrm{Aa}$ & $\mathrm{Aa}$ & 40 & 6 & 33 & 13 & $4.0^{\star}$ & 0.9 \\
\hline E5f157 & aa & $\mathrm{Aa}$ & 13 & 33 & 24 & 22 & $8.7^{* \star}$ & 3.5 \\
\hline B8f234 & $\mathrm{Aa}$ & $\mathrm{Aa}$ & 43 & 3 & 32 & 14 & $10.9 * \star \star$ & 2.1 \\
\hline E9f147 & $\mathrm{Aa}$ & $\mathrm{Aa}$ & 40 & 6 & 37 & 9 & $4.0^{*}$ & 3.7 \\
\hline E9f368 & aa & $\mathrm{Aa}$ & 9 & 37 & 28 & 18 & $17.0^{\star * *}$ & 3.5 \\
\hline E9f371 & $\mathrm{Aa}$ & aa & 31 & 15 & 22 & 24 & $5.6^{*}$ & 2.1 \\
\hline A12f288 & $\mathrm{Aa}$ & $\mathrm{Aa}$ & 43 & 3 & 33 & 13 & $10.9 * * *$ & 2.8 \\
\hline A12f429 & $\mathrm{Aa}$ & $\mathrm{Aa}$ & 25 & 21 & 38 & 8 & $9.2^{\star \star}$ & 2.1 \\
\hline B12f52 & aa & $\mathrm{Aa}$ & 16 & 30 & 21 & 25 & $4.3^{\star}$ & 3.5 \\
\hline B12f243 & aa & $\mathrm{Aa}$ & 37 & 9 & 17 & 29 & $17.0^{* \star *}$ & 2.8 \\
\hline B12f478 & $\mathrm{Aa}$ & aa & 31 & 15 & 22 & 24 & $5.6^{*}$ & 2.1 \\
\hline C1f99 & aa & $\mathrm{Aa}$ & 37 & 9 & 18 & 28 & $17.0^{* * *}$ & 3.5 \\
\hline D1f129 & $\mathrm{Aa}$ & $\mathrm{Aa}$ & 42 & 4 & 33 & 13 & $8.1^{\star *}$ & 2.1 \\
\hline D1f162 & $\mathrm{Aa}$ & aa & 31 & 15 & 23 & 23 & $5.6^{\star}$ & 2.8 \\
\hline D1f203 & $\mathrm{Aa}$ & $\mathrm{Aa}$ & 22 & 24 & 40 & 6 & $15.5^{\star \star \star}$ & 2.8 \\
\hline D1f328 & aa & $\mathrm{Aa}$ & 12 & 34 & 30 & 16 & $10.5^{\star \star}$ & 0.7 \\
\hline C5f112 & $\mathrm{Aa}$ & aa & 31 & 15 & 24 & 22 & $5.6^{\star}$ & 3.5 \\
\hline D5f203 & $\mathrm{Aa}$ & $\mathrm{Aa}$ & 40 & 6 & 37 & 9 & $4.0^{*}$ & 3.7 \\
\hline
\end{tabular}

Table 5 Survival analysis results, hazard ratio and LRANK. R: resistance marker, S: susceptible marker; $\mathrm{O}_{a}$ : total number of dead offspring in the band-absent marker 
phenotype and $E_{a}$ its relative expected count; $O_{p}$ : total number of dead offspring in the band-present marker phenotype and $E_{p}$ its relative expected count. *: $p<0.05,{ }^{*}: p<0.01$, $\star \star \star *: p<0.001$.

\begin{tabular}{|c|c|c|c|c|c|c|c|c|}
\hline Marker & Origin & $\mathrm{R} / \mathrm{S}$ & $\mathrm{O}_{\mathrm{a}}$ & $\mathrm{E}_{\mathrm{a}}$ & $\mathrm{O}_{\mathrm{p}}$ & $E_{p}$ & $\begin{array}{l}\text { Hazard } \\
\text { ratio }(h)\end{array}$ & LRANK \\
\hline A1f150 & W31, 410-8 & $\mathrm{S}$ & 12 & 21.8 & 33 & 24.2 & 0.40 & $7.7^{\star \star}$ \\
\hline E1f43 & $703-29,410-7,410-8$ & $\mathrm{R}$ & 21 & 10.0 & 25 & 36.0 & 0.33 & $15.5^{\star \star \star}$ \\
\hline A3f73 & $703-29,410-8$ & $\mathrm{R}$ & 34 & 24.2 & 12 & 21.8 & 0.39 & $8.4^{\star \star}$ \\
\hline E3f169 & W31, 410-8 & $\mathrm{R}$ & 36 & 24.1 & 10 & 21.9 & 0.31 & $12.3^{\star \star \star}$ \\
\hline E3f255 & $703-29,410-7,410-8$ & $\mathrm{R}$ & 21 & 9.5 & 25 & 36.5 & 0.31 & $17.6^{\star \star \star}$ \\
\hline E5f157 & $703-29,410-8$ & $\mathrm{R}$ & 33 & 24.5 & 13 & 21.5 & 0.45 & $6.4^{*}$ \\
\hline B8f234 & $703-29,410-7,410-8$ & $\mathrm{~S}$ & 3 & 10.1 & 43 & 35.9 & 0.25 & $6.4^{*}$ \\
\hline E9f368 & W31, 410-8 & $\mathrm{R}$ & 37 & 23.6 & 9 & 22.4 & 0.26 & $15.6^{\star \star \star}$ \\
\hline A12f288 & $703-29,410-7,410-8$ & $\mathrm{~S}$ & 3 & 9.5 & 43 & 36.5 & 0.27 & $5.5^{\star}$ \\
\hline A12f429 & $703-29,410-7,410-8$ & $\mathrm{R}$ & 21 & 10.0 & 25 & 36.0 & 0.33 & $15.5^{\star \star \star}$ \\
\hline B12f243 & $703-29,410-8$ & $\mathrm{~S}$ & 9 & 23.1 & 37 & 22.9 & 0.24 & $17.3^{\star \star \star}$ \\
\hline C1f99 & $703-29,410-8$ & $\mathrm{~S}$ & 9 & 22.4 & 37 & 23.6 & 0.26 & $15.6^{\star \star \star}$ \\
\hline D1f129 & $703-29,410-7,410-8$ & $\mathrm{~S}$ & 4 & 9.7 & 42 & 36.3 & 0.36 & $4.3^{*}$ \\
\hline D1f203 & W31, 410-7, 410-8 & $\mathrm{R}$ & 24 & 12.6 & 22 & 33.4 & 0.34 & $14.3^{\star \star \star}$ \\
\hline D1f328 & W31, 410-8 & $\mathrm{R}$ & 34 & 21.5 & 12 & 24.5 & 0.31 & $13.7^{\star \star \star}$ \\
\hline
\end{tabular}

Table 6 Length, number of markers, average spacing and largest interval between markers in linkage groups of the $410 \_7$ parental map in 0 . edulis established with CriMap.

\begin{tabular}{lllll}
\hline Linkage group & Length (cM) & $\begin{array}{l}\text { No. } \\
\text { markers }\end{array}$ & $\begin{array}{l}\text { of } \\
\text { spacing }(\mathrm{cM})\end{array}$ & $\begin{array}{l}\text { Largest } \\
(\mathrm{cM})\end{array}$ \\
\hline LG1_410_7 & 83.9 & 11 & 8.39 & 38.9 \\
LG2_410_7 & 70.2 & 10 & 7.8 & 33.3 \\
LG3_410_7 & 70.1 & 25 & 2.92 & 16.7 \\
LG4_410_7 & 59.6 & 23 & 2.71 & 17.0 \\
LG5_410_7 & 49.1 & 10 & 5.46 & 14.5 \\
LG6_410_7 & 45.2 & 12 & 4.11 & 19.4 \\
LG7_410_7 & 33.0 & 9 & 4.13 & 10.8 \\
LG8_410_7 & 19.9 & 11 & 1.99 & 12.2 \\
LG9_410_7 & 19.5 & 5 & 4.88 & 12.0 \\
LG10_410_7 & 15.1 & 11 & 1.51 & 8.6 \\
\hline Total & 465.6 & 127 & & \\
\hline
\end{tabular}

Table 7 Length, number of markers, average spacing and largest interval between markers in linkage groups of the 410_8 parental map in O. edulis established with CriMap.

\begin{tabular}{lllll}
\hline Linkage group & Length (cM) & $\begin{array}{l}\text { No. of } \\
\text { markers }\end{array}$ & $\begin{array}{l}\text { Average } \\
\text { spacing (cM) }\end{array}$ & $\begin{array}{l}\text { Largest } \\
\text { interval (cM) }\end{array}$ \\
\hline LG1_410_8 & 68.1 & 19 & 3.78 & 13.1
\end{tabular}




\begin{tabular}{lllll} 
LG2_410_8 & 66.1 & 10 & 7.34 & 40.9 \\
LG3_410_8 & 61.5 & 13 & 5.12 & 20.4 \\
LG4_410_8 & 54.1 & 15 & 3.86 & 14.7 \\
LG5_410_8 & 51.7 & 4 & 17.2 & 35.0 \\
LG6_410_8 & 46.1 & 17 & 2.88 & 8.6 \\
LG7_410_8 & 45.0 & 6 & 9.0 & 24.0 \\
LG8_410_8 & 24.0 & 6 & 4.8 & 22.9 \\
LG9_410_8 & 13.2 & 4 & 4.4 & 9.9 \\
LG10_410_8 & 11.0 & 4 & 3.67 & 11.0 \\
\hline Total & 98 & 386.7 & & \\
\hline
\end{tabular}

Table 8 Results from fitting a single QTL for the parent 410_7 (QTL express software). Threshold p 0.05 and threshold $\mathrm{p} 0.01$ correspond to chromosome-wide significance thresholds at $\alpha=5 \%$ and $1 \%$ after performing 1000 permutations.

\begin{tabular}{|c|c|c|c|c|c|}
\hline \multirow[t]{2}{*}{ Linkage group } & \multicolumn{3}{|l|}{ F ratios } & \multirow{2}{*}{$\begin{array}{l}\text { Location } \\
\text { (cM) }\end{array}$} & \multirow{2}{*}{$\begin{array}{l}\text { Paternal } \\
\text { estimate } \\
\text { (standard error) }\end{array}$} \\
\hline & $\begin{array}{l}\text { Threshold } \\
\text { p } 0.05\end{array}$ & $\begin{array}{l}\text { Threshold } \\
\text { p } 0.01\end{array}$ & Observed & & \\
\hline LG2_410_7 & 6.78 & 9.87 & 83.65 & 0 & $0.3574(0.039)$ \\
\hline LG3_410_7 & 7.97 & 12.14 & 5.57 & 0 & $-0.134(0.057)$ \\
\hline LG4_410_7 & 6.63 & 11.72 & 6.73 & 24 & $-0.1601(0.062)$ \\
\hline LG6_410_7 & 6.65 & 10.65 & 6.65 & 8 & $-0.1329(0.051)$ \\
\hline
\end{tabular}

Table 9 Results from fitting a single QTL for the parent 410_8 (QTL express software). Threshold p 0.05 and threshold p 0.01 correspond to chromosome-wide significance thresholds at $\alpha=5 \%$ and $1 \%$ after performing 1000 permutations.

\begin{tabular}{|c|c|c|c|c|c|}
\hline \multirow[t]{2}{*}{ Linkage group } & \multicolumn{3}{|l|}{ F ratios } & \multirow{2}{*}{$\begin{array}{l}\text { Location } \\
\text { (cM) }\end{array}$} & \multirow{2}{*}{$\begin{array}{l}\text { Maternal } \\
\text { estimate } \\
\text { (standard error) }\end{array}$} \\
\hline & $\begin{array}{l}\text { Threshold } \\
\text { p } 0.05\end{array}$ & $\begin{array}{l}\text { Threshold } \\
\text { p } 0.01\end{array}$ & Observed & & \\
\hline LG3 4108 & 7.22 & 12.08 & 8.17 & 61 & $-0.149(0.052)$ \\
\hline LG6_410_8 & 7.96 & 12.14 & 22.19 & 17 & $0.229(0.049)$ \\
\hline
\end{tabular}


Figures 

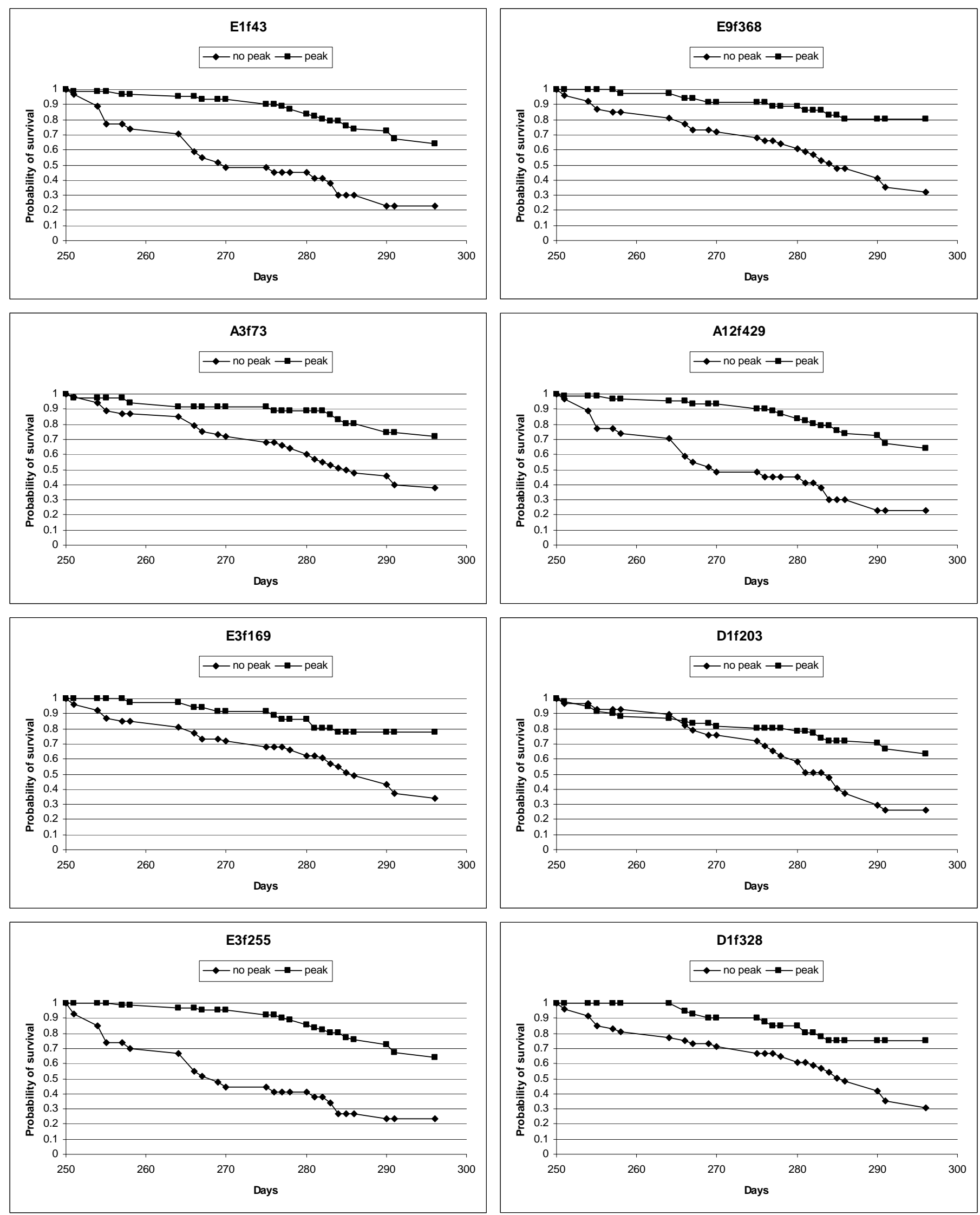

Figure 1 
Figure 1. Kaplan-Meier survival curves for eight AFLP markers $(p<0.01)$ for which the peak-present phenotype corresponded to a resistant allele. Days: number of days after the beginning of the challenge experiment.
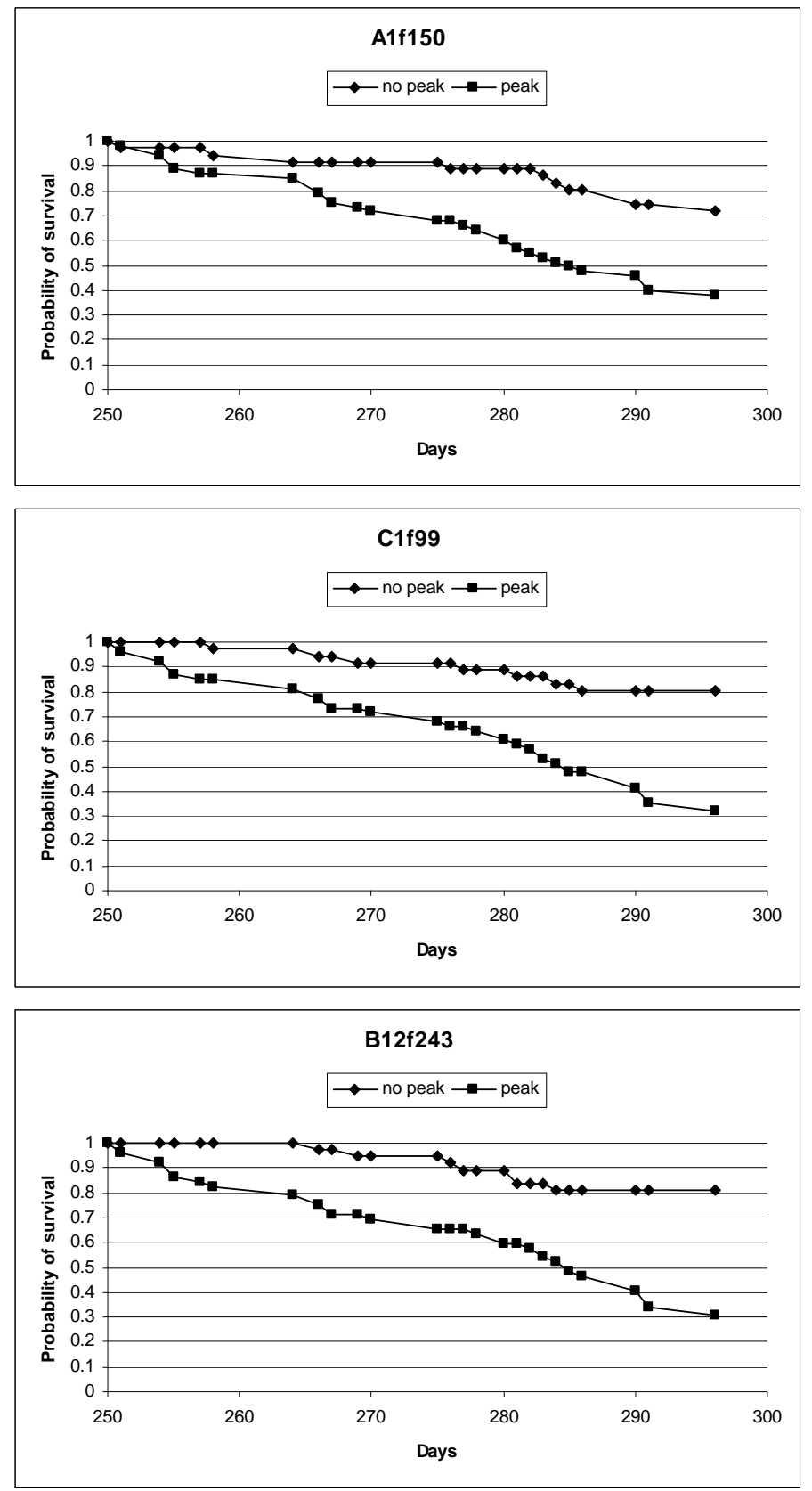

Figure 2

Figure 2. Kaplan-Meier survival curves for three AFLP markers $(p<0.01)$ for which the peak-present phenotype corresponded to a susceptible allele. Days: number of days after the beginning of the challenge experiment. 


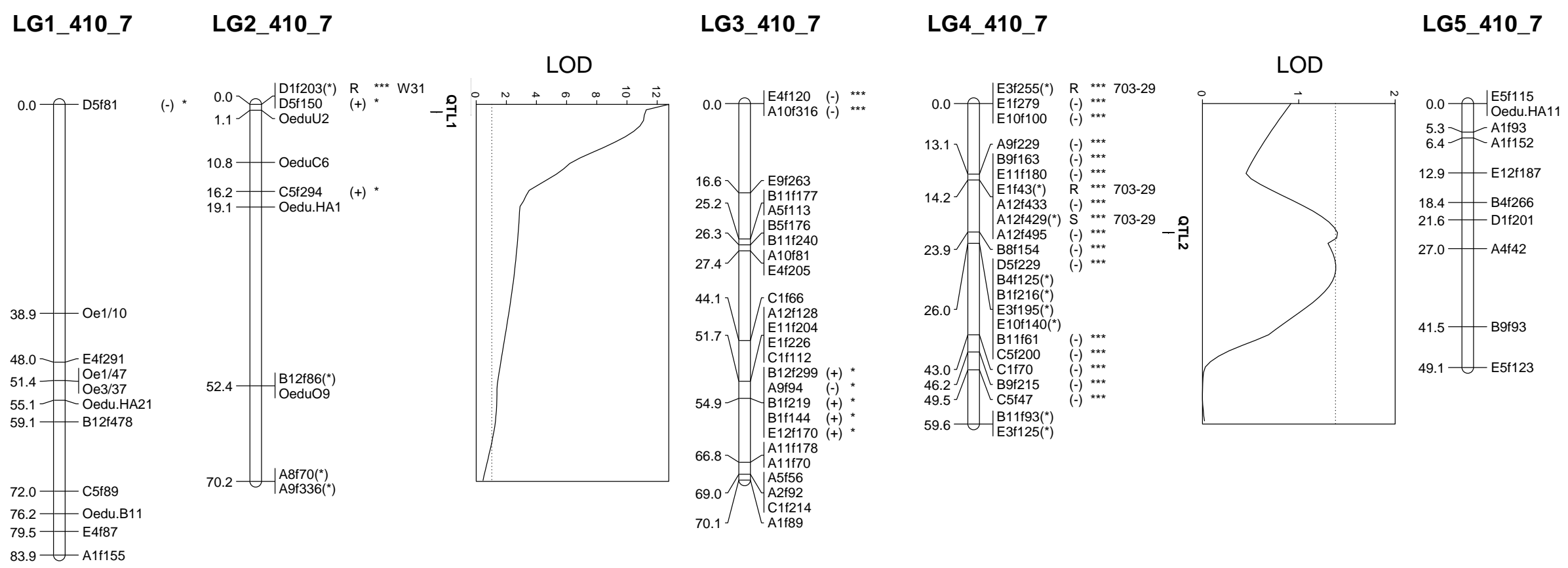

\section{LG6_410_7}

\section{LG7_410_7}

LG8_410_7 LG9_410_7

LG10_410_7
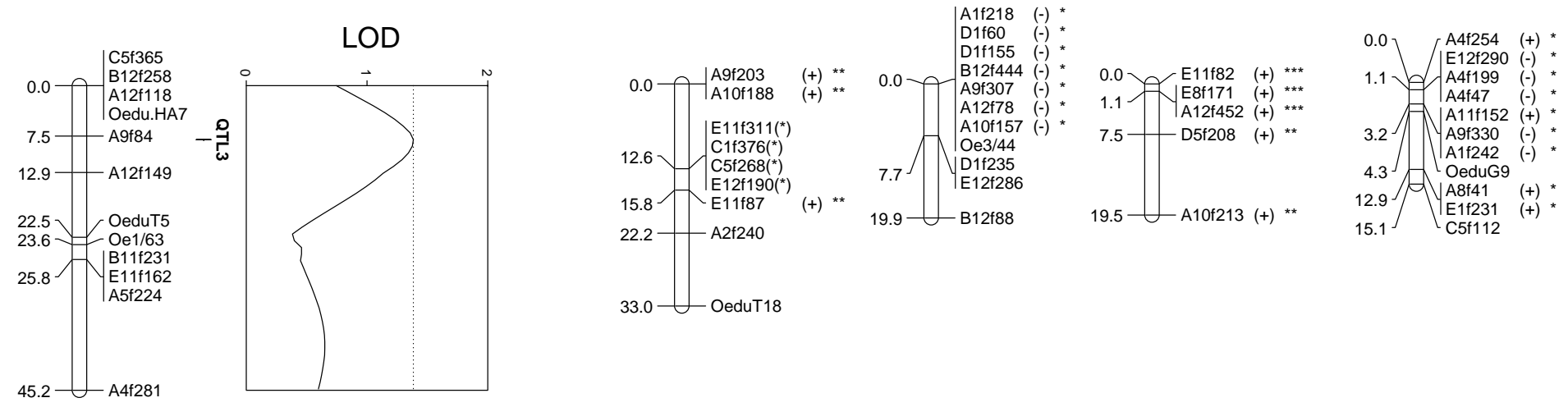

Figure 3 
Figure 3. Microsatellite and AFLP-based linkage map of the flat oyster O. edulis in the mapping family OE.F2.05.04: 410_7 parental map obtained with CriMap, 127 markers, $466 \mathrm{cM}$. AFLP markers are labelled with the primer pair name followed by the letter "f" (for fragment) and a 3-digit fragment size in base pairs. Markers are indicated on the right; and absolute positions on the left (in Kosambi $\mathrm{cM})$. On the right of AFLP locus name are specified the direction of the segregation distortion: towards a deficit (-) or excess (+) of null homozygotes with the statistical significance $\left({ }^{*} p<0.05\right.$, ${ }^{* *} p<0.01$ and $\left.{ }^{* * *} p<0.001\right)$. R: resistant marker, S: susceptible marker (detected by the approach described in Moen et al., 2004), with the statistical significance and grand-parental origin. Locus name immediately followed by an asterisk $\left(^{*}\right)$ correspond to 3:1 type AFLP. Interval mapping results for bonamiosis resistance/susceptibility are shown for linkage groups G2_410_7, G4_410_7 and G6_410_7: the LOD score is plotted against the position (cM) along the linkage group, with the dotted line representing the chromosome-wide significance threshold. 


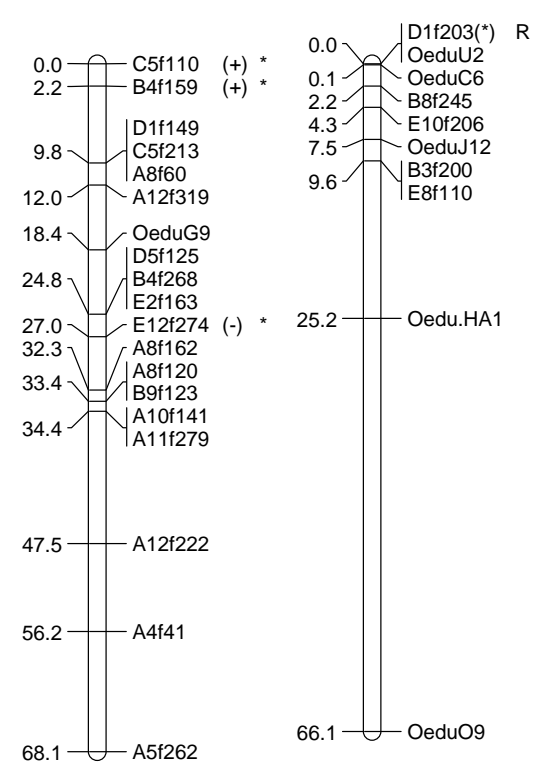

LG6_410 8

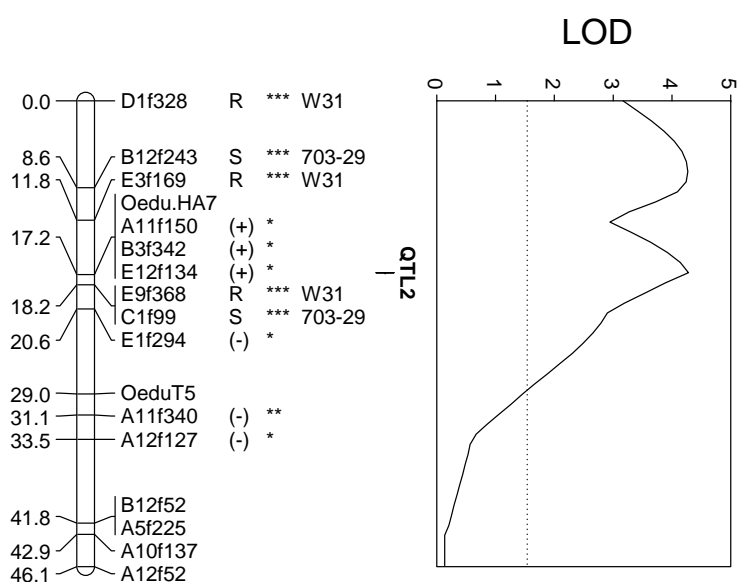

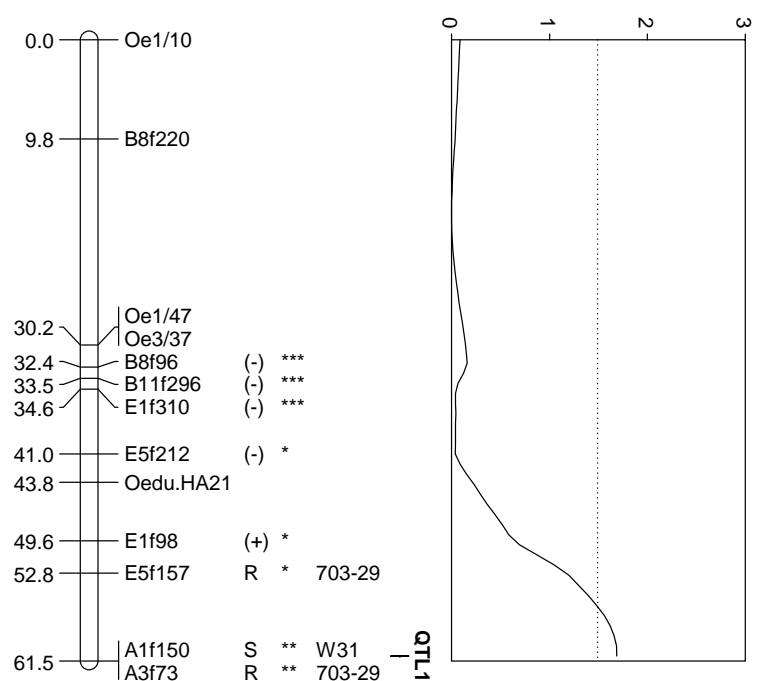

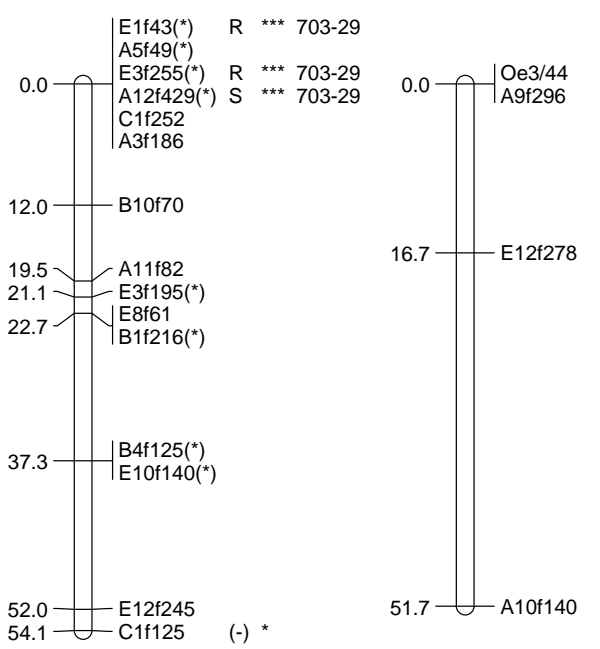

\section{LG7_410_8 LG8_410_8 LG9_410_7 LG10_410_8}

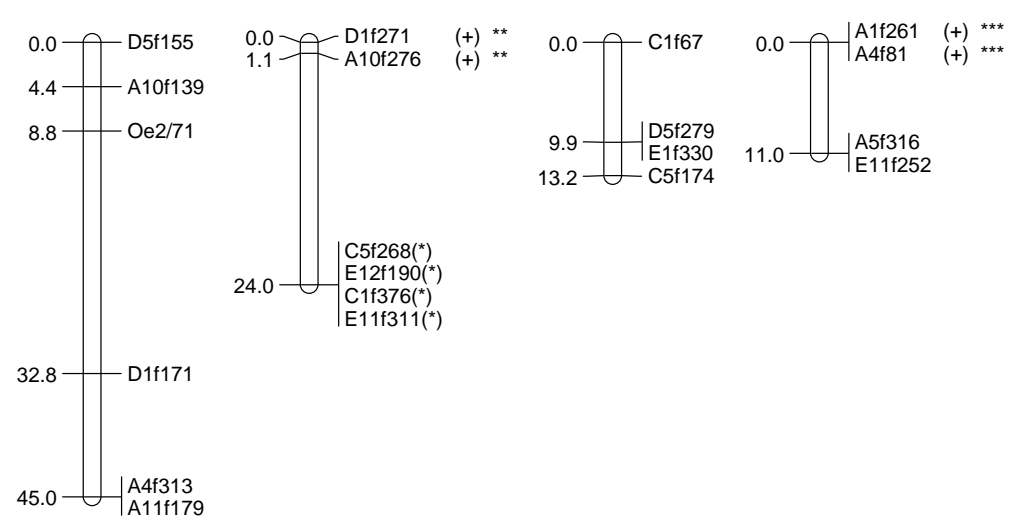


Figure 4

Figure 4. Microsatellite and AFLP-based linkage map of the flat oyster O. edulis in the mapping family OE.F2.05.04: 410_8 parental map obtained with CriMap, 98 markers, $387 \mathrm{cM}$. Interval mapping results for bonamiosis resistance/susceptibility are shown for linkage groups G3_410_8 and G6_410_8: the LOD score is plotted against the position (cM) along the linkage group, with the dotted line representing the chromosome-wide significance threshold. See Figure 3 for abbreviations. 